\title{
MAXIMUM ENTROPY MODELING OF FARMLAND DAMAGE CAUSED BY THE WILD BOAR (SUS SCROFA)
}

\author{
LEE, W.-S. ${ }^{1}-$ KIM, S.-O. ${ }^{2}-$ KIM, Y. ${ }^{3}-$ KIM, J.-H. ${ }^{2}-$ JANG, G.-S. ${ }^{2 *}$ \\ ${ }^{1}$ Department of Landscape Architecture, Daegu University \\ 201, Daegudae-ro, Gyeongsan-si, Gyeongsangbuk-do 38453, Republic of Korea \\ (phone: +82-10-2895-9858) \\ ${ }^{2}$ Department of Life Sciences, Yeungnam University \\ 280, Daehakro, Gyeongsan 38541 Republic of Korea \\ (phone: +82-53-810-2371; fax: +82-53-810-4618) \\ ${ }^{3}$ Department of Statistics, Kyungpook National University \\ 80, Daehakro, Bukgu, Daegu 41566, Republic of Korea \\ (phone: +82-10-4750-9794) \\ *Corresponding author \\ e-mail: sunside@ynu.ac.kr \\ (Received $17^{\text {th }}$ Sep 2017; accepted $15^{\text {th }}$ Jan 2018)
}

\begin{abstract}
Farmland damage caused by wild boars was modeled by the Maxent model using the fieldinspecting data surveyed in Gyeongnam Province of South Korea during 2012 and 2013. A total of 3,854 cases (2,286 in 2012 and 1,568 in 2013) were chosen for the model after the field inspection. The Maxent model obtained quite high AUCs exceeding 0.8, indicating that the probability derived from the model had high accuracy. The variable 'distance from forest boundary (d_forest)' revealed a higher probability for damaged areas located closer to forest boundaries. The areas damaged by wild boars were also located much closer to agricultural areas, including paddies and fields. Overall, areas located within $500 \mathrm{~m}$ of other agricultural areas showed a higher likelihood of damage by wild boars. Based on the predictions in Maxent, damage to farmland caused by wild boars was more closely related to distance from its habitat (i.e., forest) and use of land as food resources (i.e., rice paddies and fields) than topographical factors such as elevation and slope.
\end{abstract}

Keywords: spatial modeling, presence-only data, Maxent, machine-learning modeling

\section{Introduction}

The "Injurious Animal Destruction" program introduced during the Japanese occupation of the Korean peninsula and the Korean War (1950-1953) resulted in loss of many top predators including tigers, wolves and leopards from South Korea (Kim et al., 2011; Lee et al., 2012). Owing to the loss of top predators, wild boar populations have increased explosively in South Korea. A combination of factors have led to the rapid increase of wild boars, including changes in agricultural practices, lack of predators, reduced hunting pressure, and climate changes (Massei and Genov, 2004).

Wild boars can have a variety of impacts on the environment within and/or around their habitat, such as causing damage to agricultural land (Herrero et al., 2006) and pastures (Alexiou, 1983), as well as impacts on forest regeneration (Groot Bruinderink and Hazebroek, 1996) and predation (Pavlov et al., 1981), consumption of forest fruits (Herrero et al., 2006), and consumption of carrion (Herrero and Fernández de Luco, 2003). As there has been intensive land use and anthropogenic activities around forest patches because of insufficient land for cultivation during the last few decades in South 
Korea, the edge areas inside and outside forest patches have been rapidly exchanged for agricultural lands, including rice paddies and fields. In general, regions near forest patch boundaries are known act as buffer zones between the inside forest and human-based land uses outside the forest. These areas accommodate a variety of living things including insects, herbs and other animals. However, wild boars living inside the forest don't seem to realize the condition of the area nearby the forest after there being the land use change. Therefore, there have been conflicts between wild boars trying to obtain food and farmers who want to keep their farms free from damage. This phenomenon happened in South Korea corresponded to the opinion proposed by Peracino and Bassano (1995), and now farmland damage caused by wild boars has been a great public concern in South Korea.

As damage to farmland caused by wild boars has become a social and public concerns, the Korean government revised the act on the prevention of and countermeasures against agricultural and fisheries disasters and its enforcement regulation to include inspection of farmland damaged by harmful wild animals such as wild boars and record the information in a register at every town hall for providing a subsidy to the damage (national legislation data infrastructure center; http://www.law.go.kr). For this reason, the database of farmland damage kept in each city hall has much high accuracy in terms of the location of damage caused by wild boars; therefore, it can be applied for analysis of spatial patterns and characteristics of farmland damage caused by wild boars.

Information regarding farmland damage caused by wild boars can be transformed into a binary type of response variable for spatial modeling. At this time, various forms of regression analyses can be applied to predicting and modeling the farmland damage caused by wild boars. Recently, generalized linear models (GLM; McCullagh and Nelder, 1989; Friston et al., 1995), generalized additive models (GAM; Guisan et al., 2002) and maximum entropy (Maxent; Phillips et al., 2006) have been becoming increasingly popular for prediction of species distribution (Scott et al., 2002). The Maxent model, which is derived from a branch of statistics referred to as machine learning (Yackulic et al., 2013), is a general-purpose method for making predictions or inferences from incomplete information (Phillips et al., 2006). Although the Maxent model can be applied using presence/absence data, it is well known to produce much higher confidence in the presence-only model (Yackulic et al., 2013). Thus, the data describing damage caused by wild boars can be applied in Maxent to precisely predict the probability of damage caused by wild boars. Therefore, this study initiated a new approach to investigate the farmland damage caused by wild boars using field-survey data. In this study, farmland damaged by wild boars were applied as presence-only data in a maximum entropy model (Maxent) to estimate the spatial patterns and sensitivity of wild boars in farmland. The results presented herein will be useful to managing the wild boar population on the Korean peninsula and provide ideas to facilitate co-existence of wild boars and humans.

\section{Materials and methods}

\section{Study species (wild boar) and data sources}

The wild boar is a large mammal that has one of the broadest geographic distributions, and can occupy a wide range of environments, including semi-deserts, wetlands, high mountain environments, and forests. Although the wild boar is a 
generalist omnivore that can feed on a wide variety of foods for which the availability in space and time is not constant (Herrero et al., 2006), this study focused on farmlands that were near forests and sensitive to damage caused by wild boars.

Data describing damage caused to farmland by wild boars was collected in Gyeongnam Province $\left(\right.$ area $=10,537.32 \mathrm{~km}^{2}$ ), which is located in southeastern South Korea. The damage data has higher confidence because it was recorded in the register after inspection of individual fields for damage caused by wild boars. A total of 2,286 cases in 2012 and 1,568 in 2013 were recorded in the register within Gyeongnam Province. The spatial location was digitalized into the spatial point (shape file), and used as presence only data for the response variable in this study (Fig. 1). The results of inspections revealed rice paddy fields were most preferred by wild boars (993 in 2012; 710 in 2013), followed by dry fields (721 in 2012; 501 in 2013).
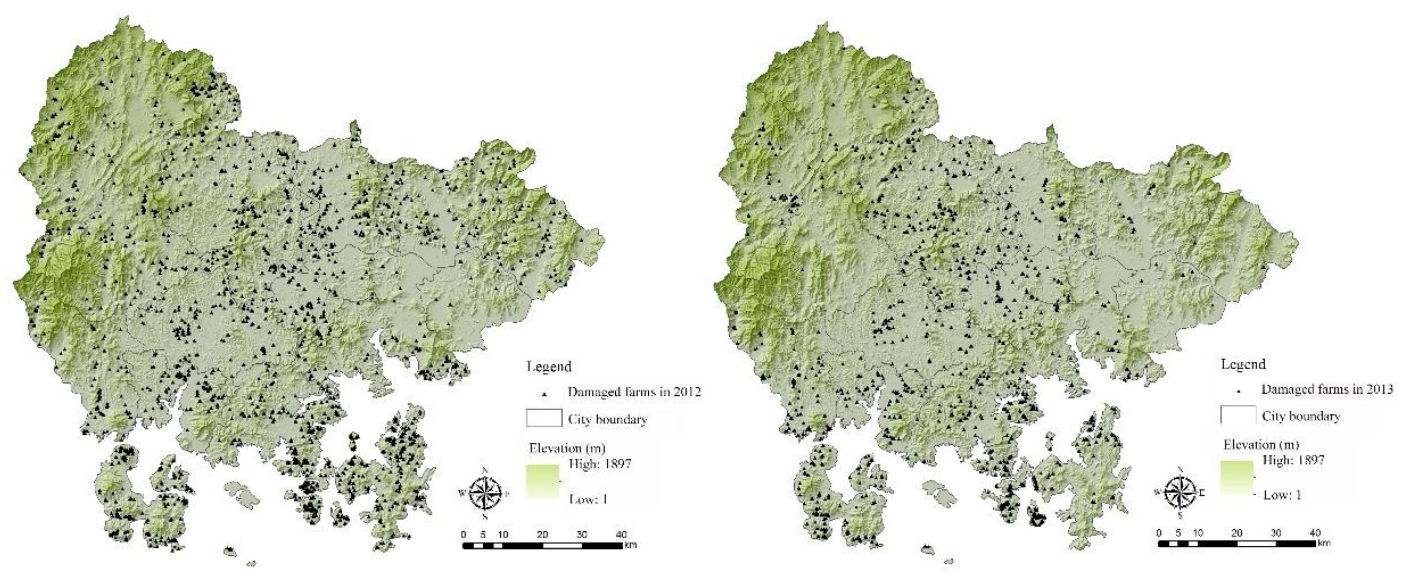

Figure 1. Distribution of farmland damaged by wild boars

\section{Environmental variables for explaining the farmland damage by wild boars}

Nine independent variables for explaining farmland damage caused by wild boars were selected based on topographical and environmental conditions around accessibility to land uses by a wild boar (Table 1).

Topographical factors could be major indicators to explain wildlife habitat (Guisan and Zimmermann, 2000) because there can be environmental variability and strong local gradients of insulation depending on topography such as elevation and surface orientation (slope, aspect and hillshade) (Fu and Rich, 2002; Kim et al., 1998; Seo et al., 2000; Polfus et al., 2011). Elevation, slope and aspect have commonly been used for modeling species distribution because different levels of solar energy could be radiated according to these topographic conditions, resulting in generation of different habitat conditions. In this study, environmental variables related to topographic factors (elevation, slope, aspect and hillshade) were obtained from a digital topographic map drawn on a scale of 1 to 5,000 (NGII, National Geographic Information Institute, Suwon, South Korea).

In general, forests are recognized as resources consisting of a variety of ecological benefits including production of food and cover (McCollin, 1998), and habitat components (Olson et al., 2004). Wild boars, which are known to have home ranges of 1.1 to $3.9 \mathrm{~km}^{2}$ (Boitani et al., 1994), are known to rest in forested habitats during 
daytime, while they forage for food in farmlands at night, which is when they cause damage (Schley et al., 2008; Lee and Lee, 2014).

Table 1. Estimates of parameters applied in the model

\begin{tabular}{|c|c|c|c|c|c|}
\hline Section & Acronym & Parameter & Type & Source & References \\
\hline \multirow{4}{*}{ Topography } & Elevation & Elevation & Continuous & DEM & $\begin{array}{l}\text { Kim et al.(1998); Seo et } \\
\text { al.(2000) }\end{array}$ \\
\hline & Slope & Slope & Continuous & DEM & $\begin{array}{c}\text { Kim et al.(1998); Seo et } \\
\text { al.(2000); Fu and Rich } \\
\text { (2002) }\end{array}$ \\
\hline & Aspect & Aspect & Continuous & DEM & $\begin{array}{c}\text { Kim et al.(1998); Seo et } \\
\text { al.(2000); ); Fu and Rich } \\
\text { (2002) }\end{array}$ \\
\hline & Hillshade & Hill shade & Continuous & DEM & $\begin{array}{l}\text { Kim et al.(1998); Seo et } \\
\text { al.(2000); Fu and Rich } \\
\text { (2002); Polfus et al., } 2011\end{array}$ \\
\hline \multirow{5}{*}{ Accessibility } & D_stream & $\begin{array}{l}\text { Distance to } \\
\text { stream }\end{array}$ & Continuous & $\begin{array}{l}\text { Land cover } \\
\text { map }\end{array}$ & $\begin{array}{l}\text { Kim et al.(2012); Song } \\
\quad \text { and Kim (2012) }\end{array}$ \\
\hline & D_forest & $\begin{array}{l}\text { Distance to } \\
\text { forest } \\
\text { (outside) }\end{array}$ & Continuous & Forest map & $\begin{array}{c}\text { Kim et al.(1998); Seo et } \\
\text { al.(2000); McCollin } \\
\text { (1998) }\end{array}$ \\
\hline & D_paddy & $\begin{array}{l}\text { Distance to } \\
\text { paddy }\end{array}$ & Continuous & Forest map & $\begin{array}{c}\text { Kim et al.(1998); Seo et } \\
\text { al.(2000) }\end{array}$ \\
\hline & D_field & $\begin{array}{l}\text { Distance to } \\
\quad \text { field }\end{array}$ & Continuous & $\begin{array}{l}\text { Land cover } \\
\text { map }\end{array}$ & $\begin{array}{l}\text { Kim et al.(2012); Song } \\
\text { and Kim (2012) }\end{array}$ \\
\hline & D_road & $\begin{array}{l}\text { Distance to } \\
\text { roads }\end{array}$ & Continuous & $\begin{array}{l}\text { Topographic } \\
\text { map }\end{array}$ & $\begin{array}{l}\text { Kim et al.(2012); Song } \\
\text { and Kim (2012) }\end{array}$ \\
\hline
\end{tabular}

Therefore, the spatial proximity from natural resources could be a criterion to measure the maximum range from which wild boars try to obtain food on farmlands, and one of the references to inspect which areas would be sensitive to damage caused by wild boars (Kim et al., 2012; Song and Kim, 2012). The spatial proximity from artificial land uses (e.g., roads, buildings and other pavements) has frequently been referred to estimate the sensitivity of wild boar's responses to artificial impacts such as noise (Kim et al., 2012; Song and Kim, 2012). This study adopted the distance from roads as an explanatory variable for the model. The road data, which included all roads except for highways and unpaved roads under $3 \mathrm{~m}$ in width, were extracted from the digital topographic map drawn on a scale of 1 to 5,000 (NGII).

Prior to model building we assessed the strength of Pearson's correlation coefficients between pairs of variables: if variables were highly correlated $(r>0.7)$ then one of the variables was removed from the set (referring to Gormley et al., 2011). A final set of nine candidate variables remained for model building. 


\section{Model building and evaluation in Maxent}

The damage information, which was registered in city halls, was gathered in 2012 and 2013. This information was used as presence-only data in the Maxent model, which is a machine learning approach based on maximum entropy (Phillips et al., 2006). Maxent has been known to perform as well as, or better than, other methods for modeling presence-only data (Elith et al., 2006). In the present study, Maxent used the presence-only data to randomly select 10,000 points ('pseudo-absence'), which were combined with topographical and environmental covariates to construct an index of habitat suitability based on a $30-\mathrm{m}$ spatial pixel ranging from 0 (least suitable habitat) to 1 (most suitable habitat). The Maxent model was also run 100 times with 0.01 in the convergence threshold, which was defined as the maximum percentage of pixels with cluster assignments that can go unchanged between iterations. Additionally, $25 \%$ of the presence data were withheld to be used as training data to evaluate the model's performance.

Model performance was assessed by determining how well the model discriminates between unsuitable and suitable areas over a range of thresholds (Fielding and Bell, 1997). A receiver operating characteristic (ROC) curve, which compares the model sensitivity (true positives) against 1-specificity (false positives) over the entire range of thresholds, was plotted to assess performance of the Maxent model. Because we only have occurrence data and no absence data, the "fractional predicted area" (the fraction of the total study area predicted present) was used instead of the more standard commission rate (fraction of absences predicted present) (Phillips et al., 2006). Additionally, the area under the ROC curve (AUC) was used to guarantee the probability that a randomly selected presence site will be ranked as more suitable than a randomly chosen pseudo-absence site for presence-only modeling (Gormley et al., 2011). An AUC of 0.5 indicates that the model performs no better than random, whereas an AUC of 1 means a model with perfect discrimination and a model with an AUC > 0.7 is considered to provide a confident result in general (Swets, 1988). An additional measure of model performance is the regularized training gain ('Gain'), which describes how much better the Maxent distribution fits the presence data compared to a uniform distribution (Gormley et al., 2011).

\section{Results}

\section{Maxent model using data describing farmland damage by wild boar}

Three variables (distance to roads, hillshade and aspect) were consistently removed in both years because of the lower $\%$ contribution $(<1 \%)$ in the preliminary Maxent modeling, and six biophysical factors were used as covariates to explain the presence of damage by wild boars. The AUC ( 0.834 for $2012 ; 0.867$ for $2013 ; 0.816$ for both) and gain ( 0.774 for $2012 ; 0.9757$ for $2013 ; 0.6736$ for both) values indicate that the Maxent models with six variables explain the farmland damage by wild boars well. The plots (Fig $3 a, 3 b$ ) of false negative rate and fractional predicted area (FPA) show little overlap which is meaning the usefulness of the Maxent models in this study. Table 2 shows that the variables d_forest and d_field made a relatively higher percent contribution to the Maxent model and three variables (d_forest, d_field and d_paddy) made an approximately $90 \%$ relative contribution to the Maxent model. These three variables were also shown to contain a substantial amount of information that was not 
contained in the other variables. Conversely, three other variables (slope, elevation and d_stream) achieved relatively lower percent contribution $(<4 \%)$ to the model for both years (Fig. 3), and achieved little gain when used alone. The results obtained when omitting each variable while including all others showed that no one variable contained a substantial amount of information that was not contained in the other variables. Therefore, the probability of presence increased with increasing d_forest, d_field and d_paddy.

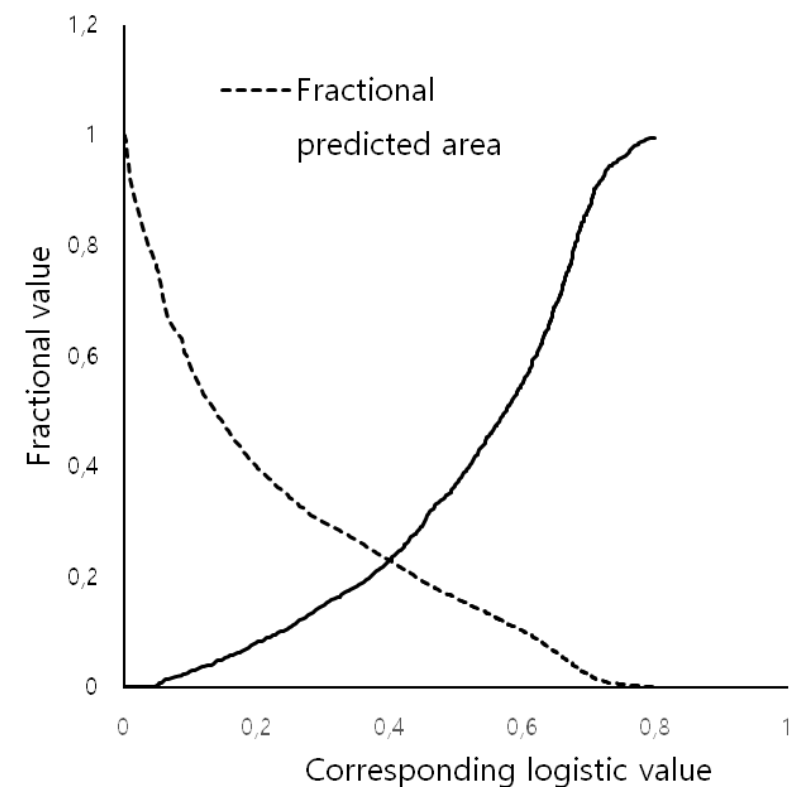

a

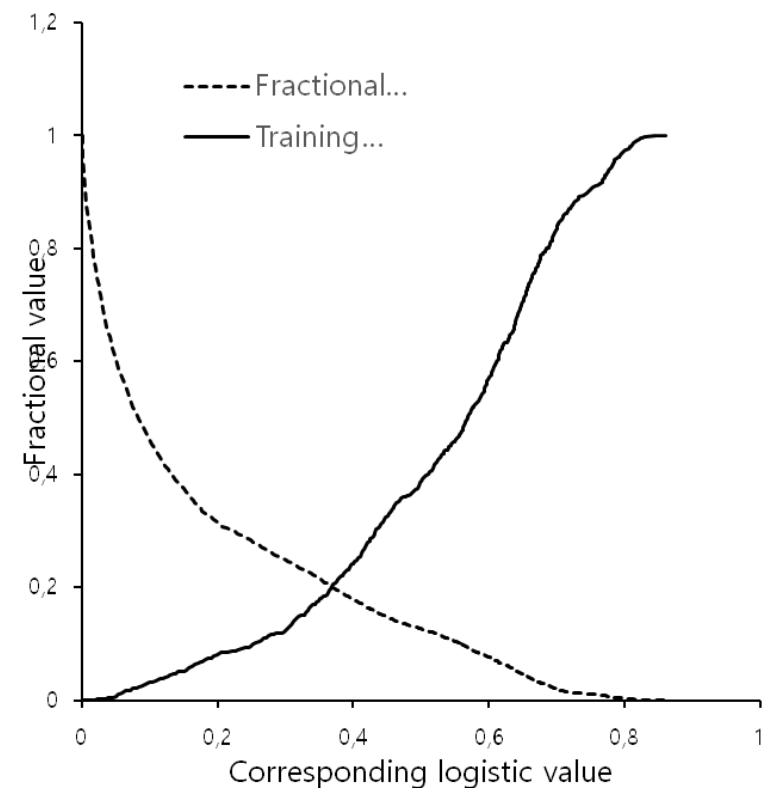

b

Figure 2. Performance of the Maxent model of farmland damage caused by wild boars in Gyeongnam Province. (a) False negative error rate (solid line) and FPA (dashed line) based on all threshold values in 2012. (b) False negative error rate (solid line) and FPA (dashed line) based on all threshold values in 2013 


\section{Partial response curves in the Maxent model}

Six pairs of partial response curves for 2012, 2013 and both years showed very consistent curvatures for the damage probability by wild boars depending on changes of each factor (Figs. 4, 5, 6). The variable d_forest was explaining that there was a higher probability for the damage area to be located close to forest boundaries. Most areas with higher damage probability were found within $500 \mathrm{~m}$ of the forest boundaries, whereas the probability was much lower close to zero at the outside area exceeding the $500 \mathrm{~m}$ distance from forest boundaries. The damage probability was also found to be dependent on elevation with the inverse correlation. Specifically, the damage probability decreased as the elevation increased, and finally there was little probability as it exceeded $800 \mathrm{~m}$ in elevation. The inclination of the farmland damage on elevation is not completely irrelevant to the distribution of farmlands per elevation in South Korea. The damage probability did not seem to be dependent on the distance to water resources. The probability was almost higher than 0.5 in general (Figs. 4d, 5d, 6d), although there were slight biases in the probability. The areas damaged by wild boars were located much closer to agricultural areas, including paddies (Fig. 4e, 5e, 6e) and fields (Figs. $4 f, 5 f, 6 f$ ). There was also higher probability of damage by wild boars in the areas distributed within $500 \mathrm{~m}$ of other agricultural areas.
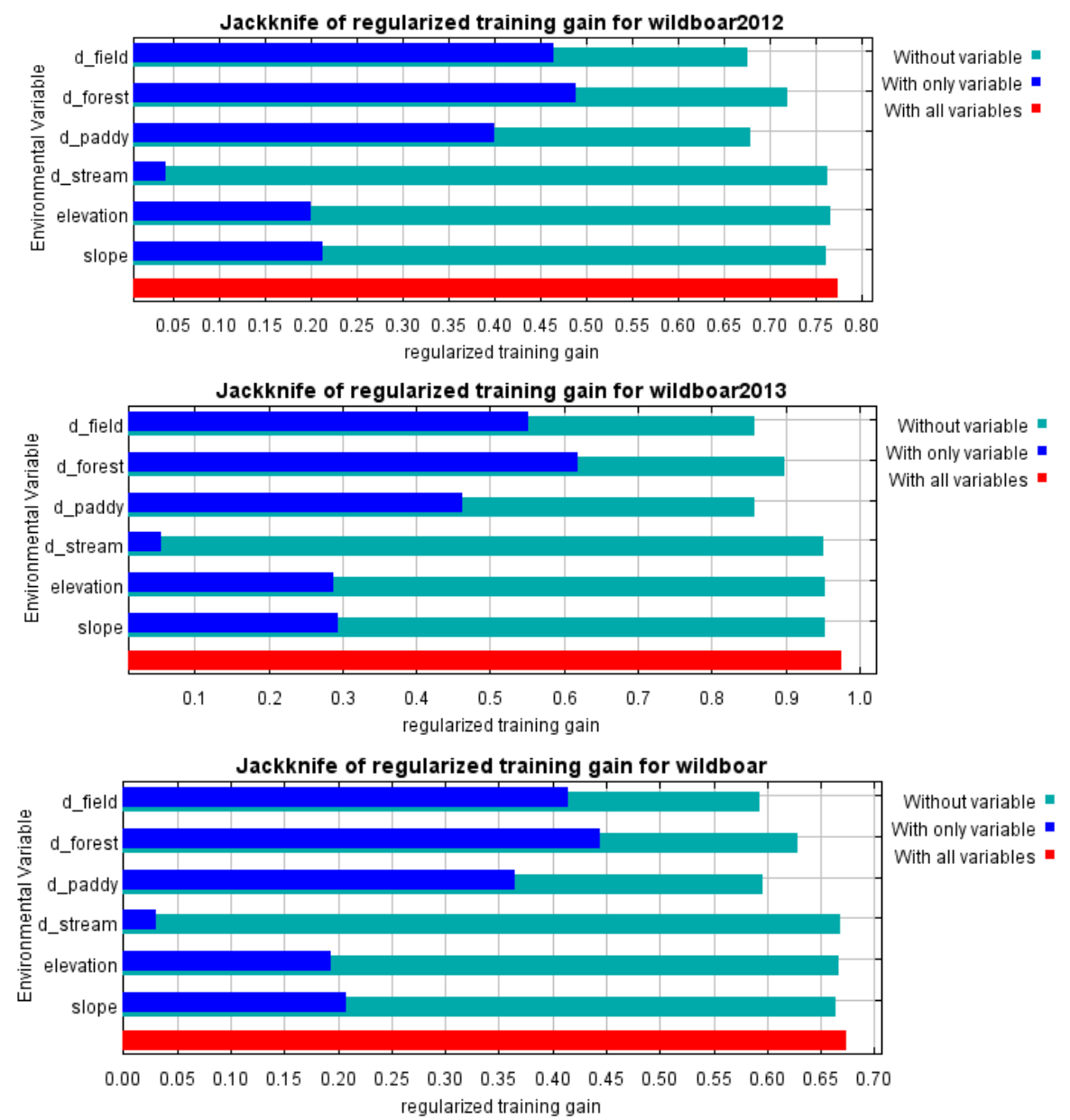

Figure 3. Jackknife regularized training gain, with only that variable and without variable from a model 


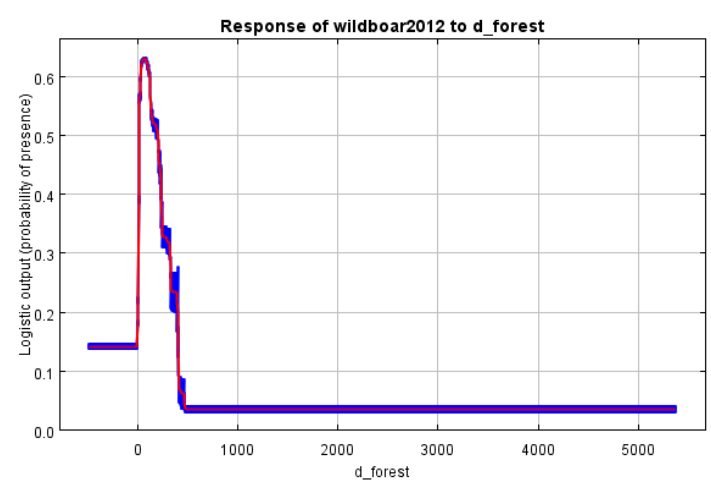

a) distance from forest patches

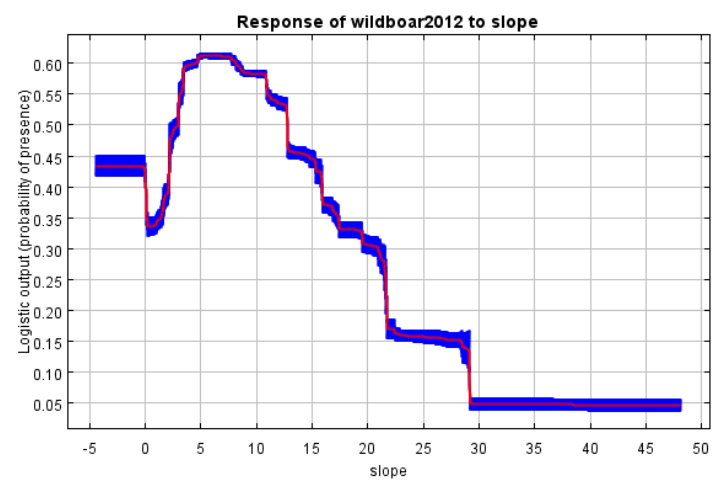

c) slope

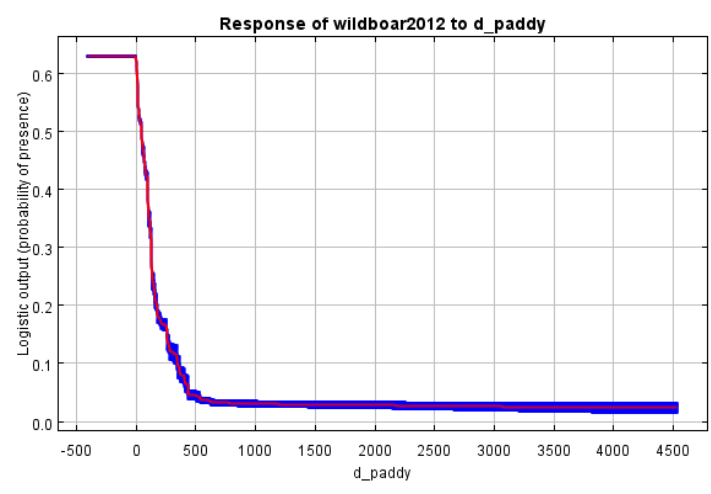

e) distance from paddy

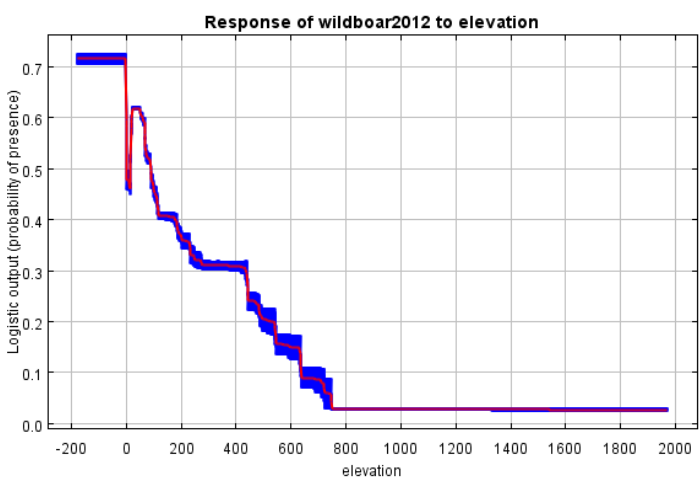

b) elevation

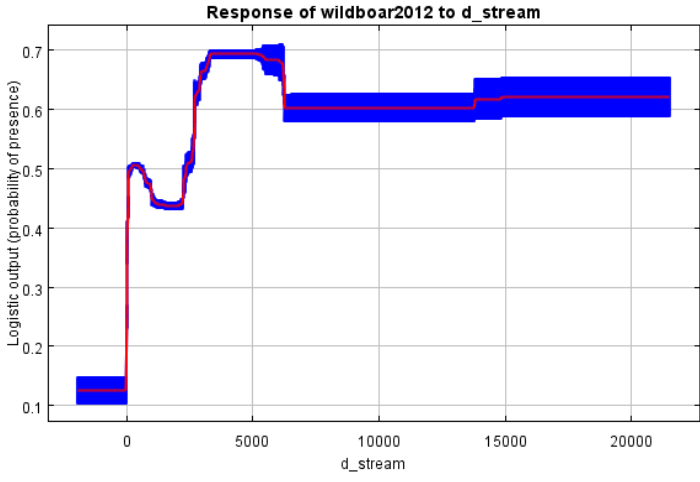

d) distance from stream

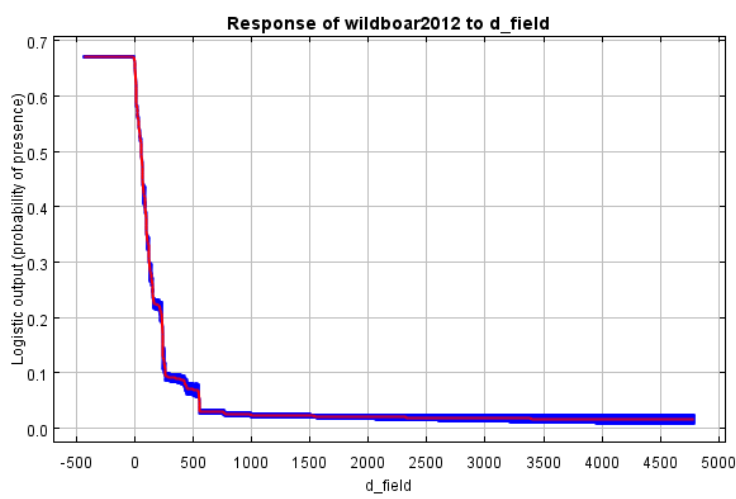

f) distance from fields

Figure 4. Partial response curve for 2012

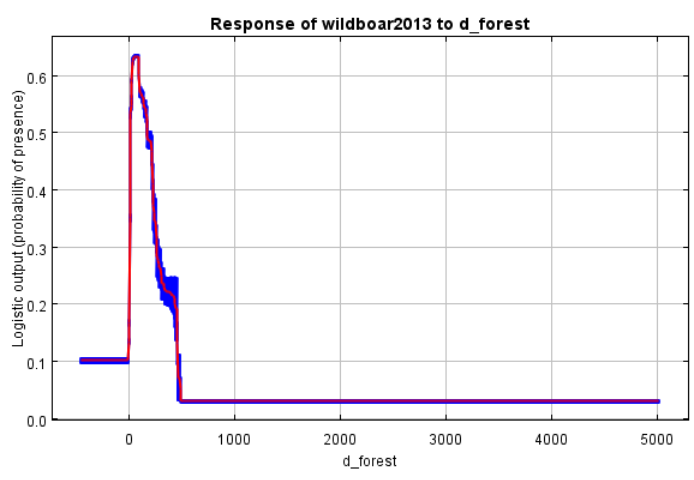

a) distance from forest patches

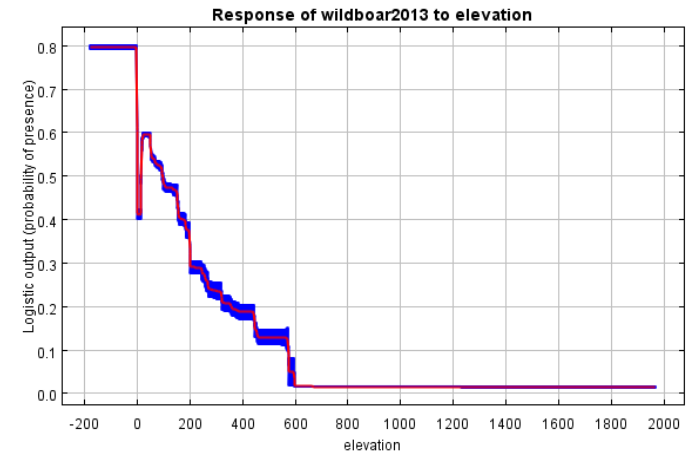

b) elevation 


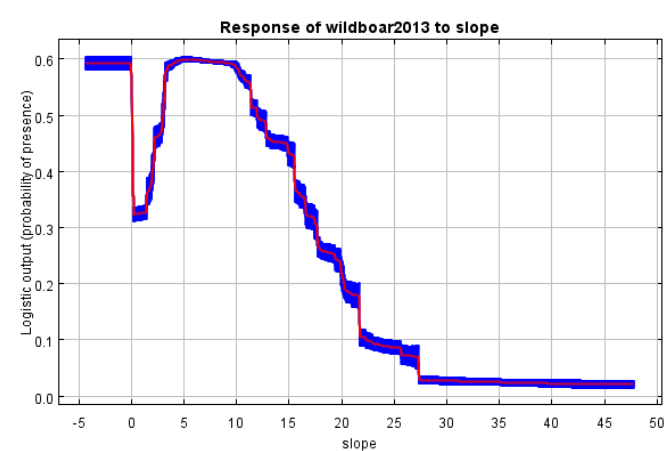

c) slope

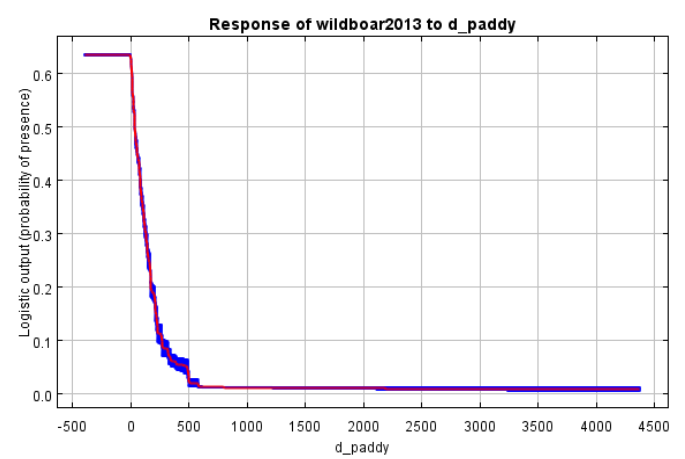

e) distance from paddy

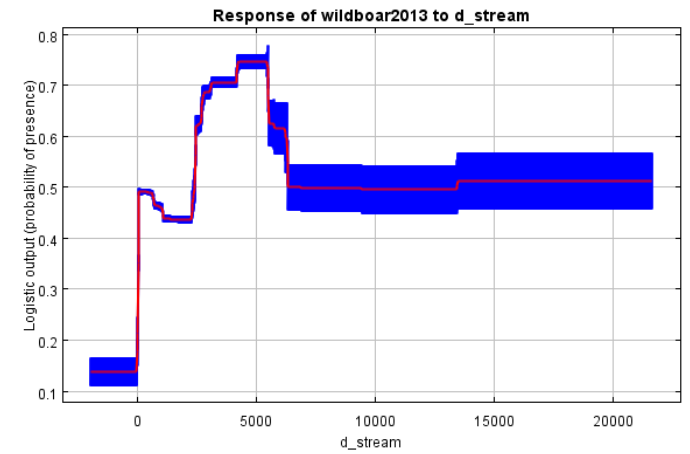

d) distance from stream

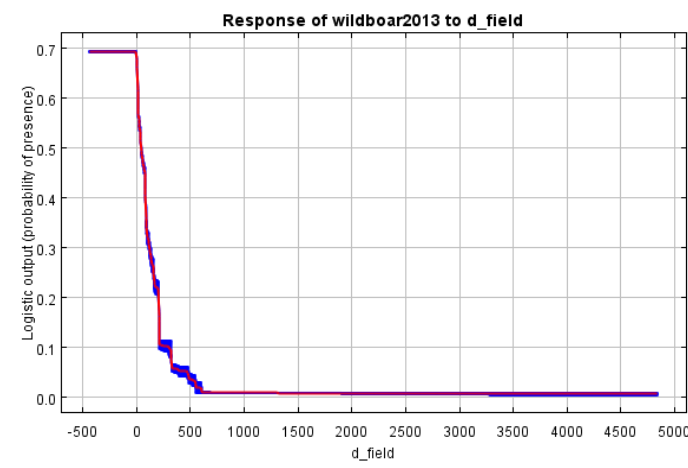

f) distance from fields

Figure 5. Partial response curve for 2013

\section{Predicting farmland damage by wild boars using the Maxent model}

There was a strong positive correlation $(\mathrm{r}=0.9814)$ between predictions for 2012 and 2013 (Fig. 7a, b). Specifically, cells with a higher damage probability index in 2012 had higher damage probabilities in 2013. In both years, prediction maps consistently indicated that areas with the highest probability of damage by wild boars were located close to forest boundaries. Although there were several large plains of relatively higher damage probability around the Nam and Nakdong rivers (e.g., Changyeong, Haman and Jinju), farmlands of higher damage potential seemed to be evenly distributed across the province. Furthermore, the probability of damage by wild boar was higher in areas near forest boundaries within some islands (e.g., the Geoje and Namhae islands) (Figs. 7a, b, c).

There was also a regional increase in damage probability between 2012 and 2013, especially for northwestern (e.g., Geochang, Hapcheon and Hamyang) and western (e.g., Hadong and Sancheong) areas with mountainous topography (Fig. 7d). Specifically, these areas had relatively higher damage probabilities in 2012 than 2013. Moreover, Geochang $\left(180.22 \mathrm{~km}^{2}\right)$, Hamyang $\left(128.94 \mathrm{~km}^{2}\right)$ and Hapcheon $\left(117.51 \mathrm{~km}^{2}\right)$ showed higher damage probability in 2012 than in 2013 (Table 3). Eastern mountainous areas (e.g., eastern Miryang) and some areas in north and south Geoje also showed much higher probability in 2012 than in 2013. None of the other areas was showing that there was a considerably large area getting a probability biased in each year. As shown in Table 2, the area of damage probability in 2012 was higher than in $2013\left(1301.49 \mathrm{~km}^{2} ; 12.35 \%\right)$, while the area of damage probability in 2013 was higher than in $2012\left(827.25 \mathrm{~km}^{2} ; 7.85 \%\right)$. 


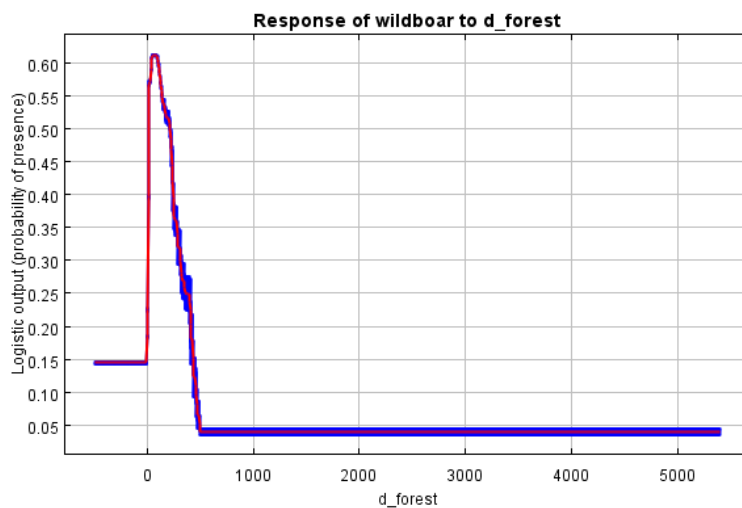

a) distance from forest patches

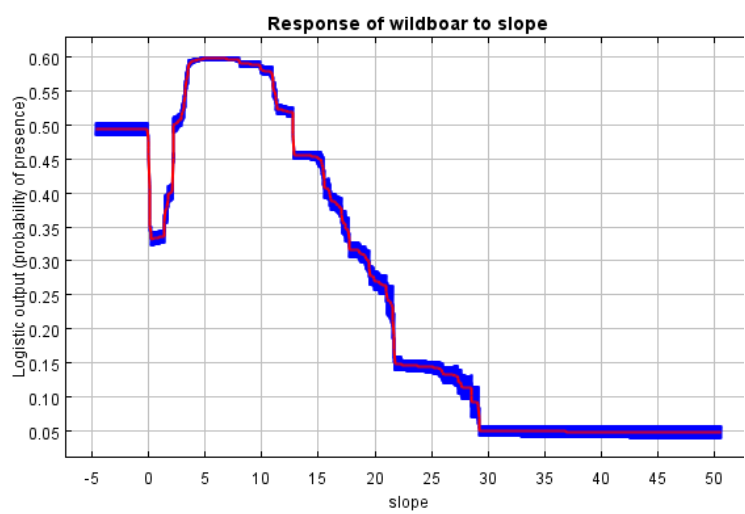

c) slope

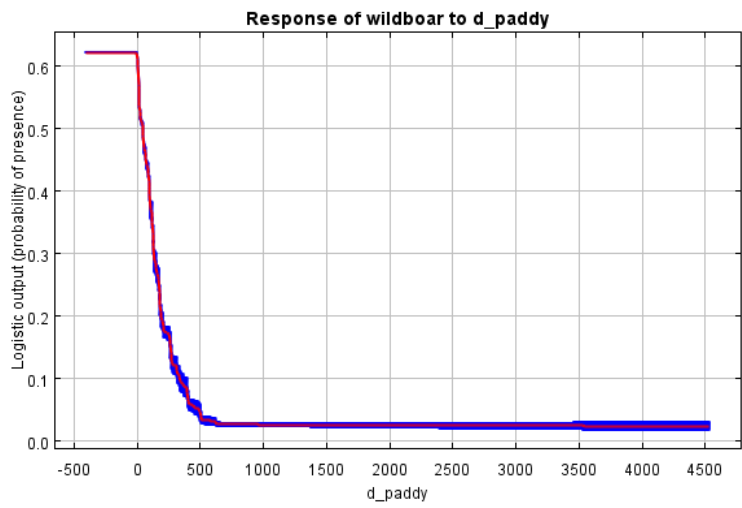

e) distance from paddy

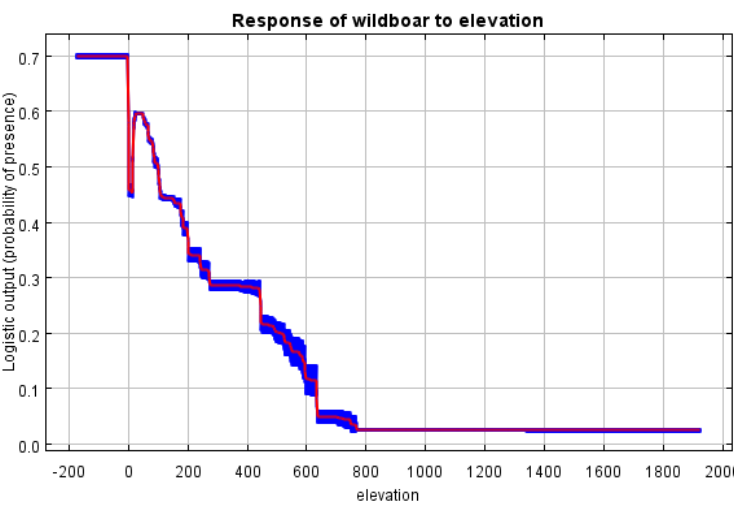

b) elevation

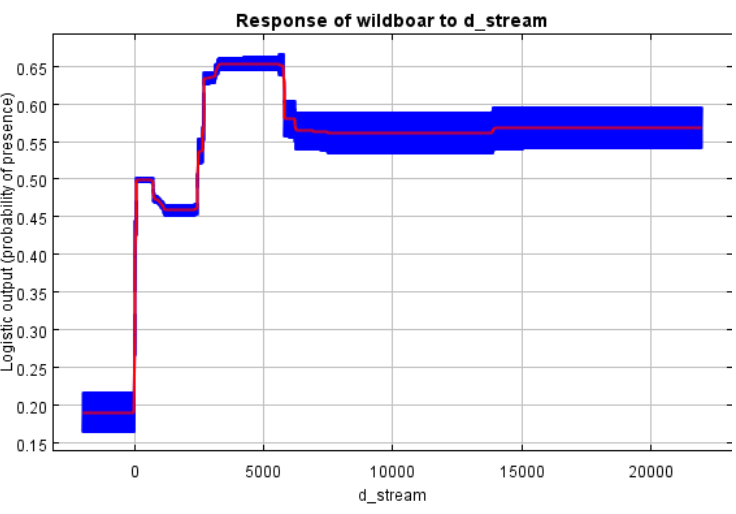

d) distance from stream

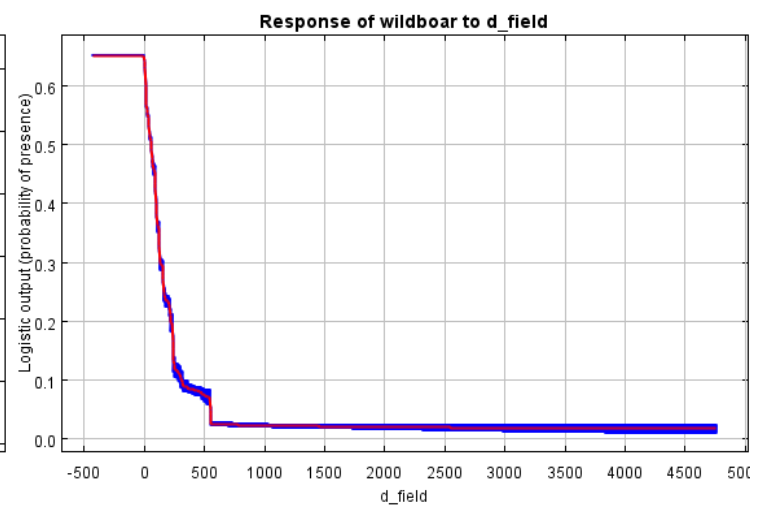

f) distance from field

Figure 6. Partial response curve for both years

Table 2. Relative contribution of variables to the Maxent model of farmland damage caused by wild boars in Gyeongnam, South Korea

\begin{tabular}{c|c|c|c}
\hline Variable & $\mathbf{2 0 1 2}$ & $\mathbf{2 0 1 3}$ & Both 2012 and 2013 \\
\hline d_forest & 35.8 & 43.0 & 40.4 \\
d_field & 38.7 & 33.9 & 37.9 \\
d_paddy & 18.7 & 13.4 & 16.5 \\
elevation & 1.3 & 4.0 & 1.6 \\
d_stream & 2.9 & 3.8 & 1.6 \\
slope & 2.6 & 2.0 & 2.0 \\
\hline
\end{tabular}




\section{Discussion}

\section{Maxent model and its accuracy using the presence-only data}

We used the presence-only data describing farmland damage by wild boars in 2012 and 2013 to estimate the damage probability; therefore, most common areas were predicted to have similar damage probability in both years. We first used the correlation coefficient and \% contribution to obtain the covariates that best explained the Maxent model so that six variables were finally selected for the model in both years after three variables were consistently removed. Three AUCs over 0.8 indicated that the Maxent models applied to estimate the damage probability had high accuracy, and the prediction maps derived from the models commonly showed the probability of damage by wild boars across the province. Based on the contribution to the model, three variables (d_forest, d_field and d_paddy) made higher contributions, while the other three variables made relatively lower contributions (Table 2). These findings indicate that the farmland damage caused by wild boars was mostly related to the distance from their habitats (i.e., forest) and land uses (i.e., rice paddy and field) rather than topographical factors such as elevation and slope. Two other variables (d_paddy and d_field) did not make a higher contribution than the variable d_forest; however, these two variables had relatively lower regularized gain without each variable based on the Jackknife test (Fig. $3)$, indicating there might be a higher loss of information estimated without each variable than others in the model. Water resources, one of major habitat components influencing wildlife, were not found to be a primary factor influencing farmland damage caused by wild boars (Table 2; Fig. 3).

\section{Characteristics of farmland damage caused by wild boars through partial response curves}

There are several reasons for frequent farmland damage caused by wild boars near forest boundaries. Fundamentally, the higher density of dominant plant species within the interior forest could suppress the growth of understory vegetation by intercepting direct sunlight. This oligotrophic condition under the crown of the dominant species within the interior forest can cause a deficit of food resources for wild boars so that they are obliged to leave the interior to find new food resources. In addition, forest patches in South Korea have been suffering from severe deforestation during the last few decades (Kwon et al., 2016). Especially, forest edge and ecotone forest have been intensively deforested and transformed into other anthropogenic land uses such as residential areas and farmland. Ecotones, which were first mentioned by Clements (1904) are defined as zonations in a habitat that obviously separates two different series of zones (Myster, 2012). Shifts in forest-grassland ecotones and their transformation imply a change of biodiversity, as well as primary and secondary productivity in there (Smith et al., 1997). Subsequent to damage to the forest edge observed in this study, wild boars lost their food and cover resources within forests. As a result, they tried to find other food resources outside the forests (Figs. 4a, 5a, 6a) including rice (Figs. 4e, 5e, 6e) and other crops (Figs. $4 f, 5 f, 6 f$ ). These findings are in accordance with the finding that wild boar most preferred rice paddies, followed by dry fields. Rapid increases in the wild boar population led to a new conflict factor between residents and wild boars in South Korea. This phenomenon was caused by the loss of top predators as mentioned by Kim et al. (2011). 


\section{Damage prediction and its bias in 2012 and 2013}

The farmland damage caused by wild boars was spread across the province. The damage was found to be most frequently within Tongyeong (302 cases in 2012, 273 cases in 2013), Geoje (238 cases in 2012, 90 cases in 2013), Namhae (204 cases in 2012, 168 cases in 2013) and Hapcheon (179 cases in 2012, 171 cases in 2013). Several factors were analyzed to determine the reason for the biased frequency of farmland damage among cities in the province (Table 3). The different ratios in the size of forest and agricultural area per city did not influence the bias of frequency of farmland damage caused by wild boars. The three cities most influenced by damage (Tongyeong, Geoje, and Namhae) were islands; however, there was no evidence to differentiate the higher damage frequency in these islands from the relatively lower frequency in other cities. Only what we have paid attention to is that the ratio of coniferous trees to others was so higher in these islands (Table 4). Coniferous trees such as Pinus thunbergii have long occupied seaside areas including these three islands because of their endurance against salt stress. The allelopathic effects of pine trees tend to exclude other species from their community (Table 4). This mechanism could strengthen the oligotrophic condition in interior forests in these islands, which could drive wild boars to find alternative food resources outside a forest. Moreover, a considerable area in the four cities mentioned above have been established as a national park in South Korea, including three island cities protected as oceanic national parks and a mountainous national park of about $70 \mathrm{~km}^{2}$ that shares its area with Hapcheon. In the region outside the protection area, there have been regular hunting fields operated by each city hall for regulating the number of wild boars. The number of wild boars has been sporadically regulated by operating hunting fields in every year, therefore, there might be doubt that the protection area can afford to accommodate relatively higher density of wild boars than other outside area so that farmlands nearby the protection area seemed more sensitive to damage by wild boars than in other regions.

Table 3. Data describing farmland damage caused by wild boars

\begin{tabular}{c|c|c|c|c|c|c|c|c}
\hline Cities & $\begin{array}{c}\text { Total area } \\
(\mathbf{T A})\left(\mathbf{k m}^{2}\right)\end{array}$ & $\begin{array}{c}\text { Forest } \\
\text { area }(\mathbf{F A}) \\
\left(\mathbf{k m}^{2}\right)\end{array}$ & $\begin{array}{c}\text { Farmland } \\
\text { area } \\
(\mathbf{F L A}) \\
\left(\mathbf{k m}^{2}\right)\end{array}$ & FA/TA & FLA/TA & FLA/FA & $\begin{array}{c}\text { Damage } \\
\text { frequency } \\
\text { in 2012 }\end{array}$ & $\begin{array}{c}\text { Damage } \\
\text { frequency } \\
\text { in 2013 }\end{array}$ \\
\hline Chanwon & 747 & 430 & 118 & $57.51 \%$ & $15.76 \%$ & $27.40 \%$ & 103 & 68 \\
Jinju & 713 & 418 & 141 & $58.61 \%$ & $19.84 \%$ & $33.86 \%$ & 115 & 85 \\
Tongyeong & 239 & 155 & 49 & $\mathbf{6 4 . 9 7 \%}$ & $\mathbf{2 0 . 4 6 \%}$ & $\mathbf{3 1 . 4 9 \%}$ & $\mathbf{3 0 2}$ & $\mathbf{2 7 3}$ \\
Sacheon & 399 & 231 & 87 & $58.03 \%$ & $21.72 \%$ & $37.43 \%$ & 116 & 90 \\
Gimhae & 463 & 237 & 99 & $51.09 \%$ & $21.26 \%$ & $41.62 \%$ & 14 & 7 \\
Miryang & 799 & 519 & 165 & $64.93 \%$ & $20.70 \%$ & $31.88 \%$ & 112 & 19 \\
Geoje & 402 & 283 & 66 & $\mathbf{7 0 . 4 8 \%}$ & $\mathbf{1 6 . 3 6 \%}$ & $\mathbf{2 3 . 2 2 \%}$ & $\mathbf{2 3 8}$ & $\mathbf{9 0}$ \\
Yangsan & 485 & 362 & 46 & $74.63 \%$ & $9.51 \%$ & $12.74 \%$ & 59 & 2 \\
Uiryeong & 483 & 331 & 90 & $68.57 \%$ & $18.69 \%$ & $27.26 \%$ & 136 & 133 \\
Haman & 417 & 212 & 118 & $50.86 \%$ & $28.38 \%$ & $55.80 \%$ & 99 & 61
\end{tabular}




\begin{tabular}{c|c|c|c|c|c|c|c|c} 
Changyeong & 533 & 285 & 147 & $53.55 \%$ & $27.56 \%$ & $51.48 \%$ & 132 & 64 \\
Goseong & 518 & 339 & 111 & $65.46 \%$ & $21.43 \%$ & $32.74 \%$ & 145 & 135 \\
Namhae & 358 & 240 & 78 & $\mathbf{6 7 . 0 8 \%}$ & $\mathbf{2 1 . 9 1 \%}$ & $\mathbf{3 2 . 6 7 \%}$ & $\mathbf{2 0 4}$ & $\mathbf{1 6 8}$ \\
Hadong & 676 & 489 & 112 & $72.32 \%$ & $16.52 \%$ & $22.84 \%$ & 86 & 130 \\
Sancheong & 795 & 618 & 97 & $77.81 \%$ & $12.18 \%$ & $15.65 \%$ & 135 & 2 \\
Hamyang & 725 & 562 & 101 & $77.42 \%$ & $13.86 \%$ & $17.91 \%$ & 83 & 54 \\
Geochang & 803 & 609 & 120 & $75.86 \%$ & $14.96 \%$ & $19.72 \%$ & 28 & 16 \\
Hapcheon & 984 & 710 & 150 & $\mathbf{7 2 . 2 2 \%}$ & $\mathbf{1 5 . 2 5 \%}$ & $\mathbf{2 1 . 1 1 \%}$ & $\mathbf{1 7 9}$ & $\mathbf{1 7 1}$ \\
\hline
\end{tabular}

Table 4. Dominant plant species and area per city

\begin{tabular}{c|c|c|c|c|c}
\hline Cities & Total & Conifer $(\%)$ & Broad leaf (ha) & Mixed (ha) & Others (ha) \\
\hline Changwon & $42,968.99$ & $15,383.95(36)$ & $5,341.88$ & $22,232.95$ & 10.22 \\
Jinju & $41,785.79$ & $18,130.36(43)$ & $5,013.23$ & $18,458.49$ & 183.71 \\
Tongyeong & $15,542.25$ & $11,182.00(72)$ & 437.46 & $3,922.79$ & - \\
Sacheon & $23,130.13$ & $10,548.60(46)$ & $2,498.19$ & $9,918.65$ & 164.69 \\
Gimhae & $23,675.28$ & $8,512.61(36)$ & $3,953.39$ & $11,168.23$ & 41.06 \\
Myrang & $51,853.49$ & $24,451.74(47)$ & $14,203.96$ & $13,138.48$ & 59.31 \\
Geoje & $28,335.29$ & $12,566.58(44)$ & $4,957.47$ & $10,701.35$ & 109.90 \\
Yangsan & $36,223.15$ & $7,450.41(21)$ & $19,022.67$ & $9,691.97$ & 58.10 \\
Uiryeong & $33,110.40$ & $17,003.56(51)$ & $3,476.97$ & $12,526.98$ & 102.89 \\
Haman & $21,189.52$ & $11,609.69(55)$ & $1,365.15$ & $8,188.89$ & 25.79 \\
Changyeong & $28,529.70$ & $20,435.58(72)$ & $1,163.21$ & $6,929.92$ & 0.99 \\
Goseong & $33,888.65$ & $20,314.60(60)$ & $3,054.70$ & $10,459.09$ & 60.26 \\
Namhae & $23,984.83$ & $15,017.27(63)$ & $1,751.34$ & $7,210.92$ & 5.30 \\
Hadong & $48,851.59$ & $18,161.36(37)$ & $15,318.61$ & $14,717.24$ & 654.37 \\
Sancheog & $61,844.62$ & $29,131.06(47)$ & $23,179.32$ & $9,195.35$ & 338.90 \\
Hamyang & $56,165.10$ & $30,794.38(55)$ & $17,428.49$ & $7,917.56$ & 24.67 \\
Geochang & $60,928.35$ & $25,042.58(41)$ & $9,073.14$ & $26,810.63$ & 2.00 \\
Hapcheon & $71,028.71$ & $29,443.23(41)$ & $8,585.18$ & $32,815.41$ & 184.89 \\
\hline
\end{tabular}

The reason for the regional bias between 2012 and 2013 may have been a difference in the number of acorns dropped in the autumn between the two years. According to field sampling conducted during the last several years (from 2010 to 2015), there has been biased acorn fall between odd and even years, with odd years showing relatively low 
acorn fall in autumn, while there was large acorn fall in the even years that might have provided sufficient food to support wild boars through the upcoming winter, spring and summer. Indeed, the large acorn fall in the autumn of 2012 might have allowed the wild boars to survive in the forest through the warmer seasons in 2013, which could have led to a lower frequency of farmland damage caused by the wild boar in 2013 (Fig. 7).
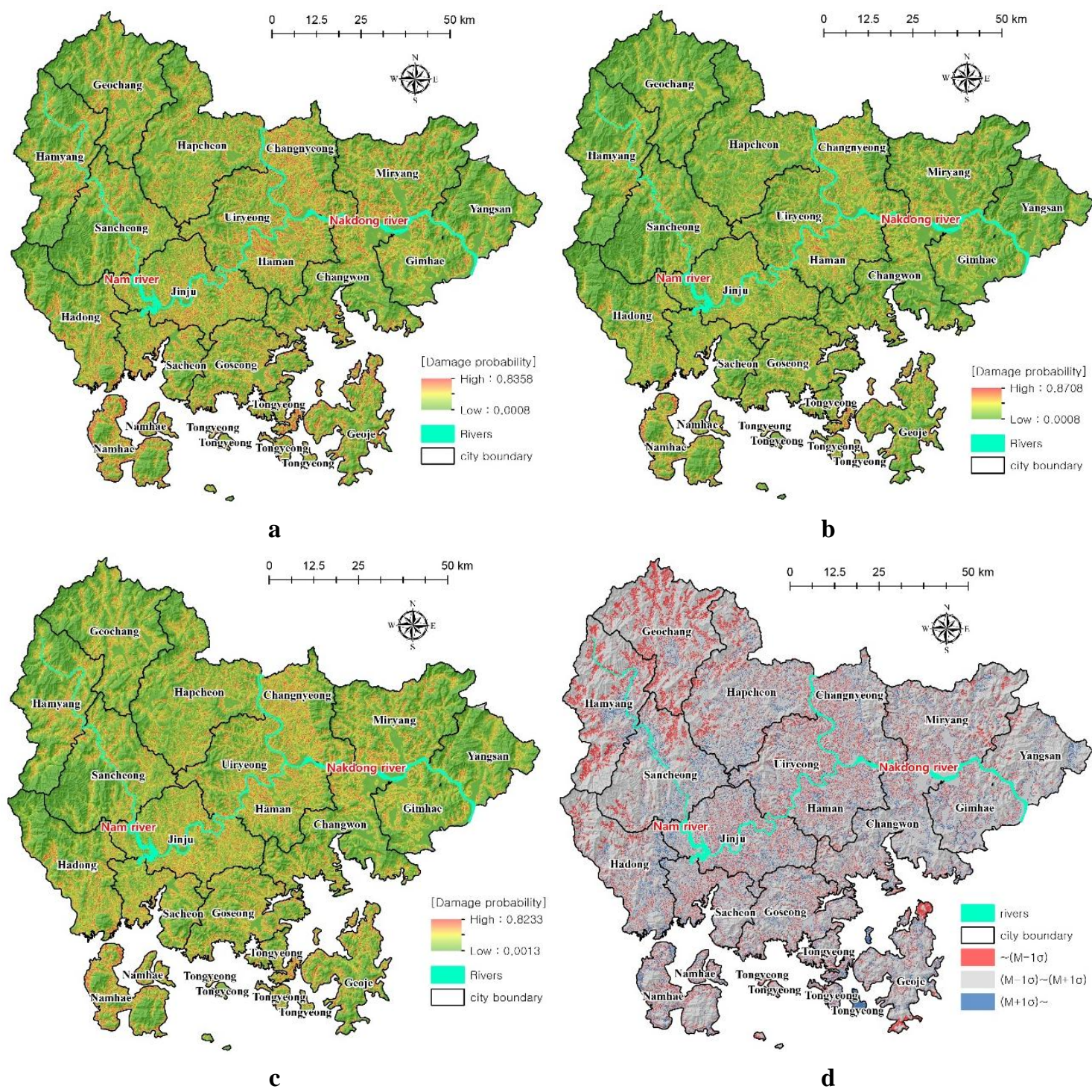

Figure 7. Predictions of farmland damage by wild boar using the Maxent model. (a) Prediction map for 2012. (b) Prediction map for 2013. (c) Prediction map for both years. (d) Difference in damage probability between 2012 and 2013 (M: mean, $\sigma$ : Stdev.). The map was the prediction map in 2013 subtracted from the one in 2012

\section{Conclusion}

Sudden increase of wild boar population and the side effect on ecosystems and farmlands have emerged as a big concern in the South Korean society. Based on the Maxent modeling with AUC over 0.8, farmlands nearby forest boundaries were known to have the higher sensitivity to the farmland damage by wild boars rather than other 
farms. It was assumed that indiscreet and unilateral development of forest edge areas, which has done during the last several decades, was responsible for abrupt and nationwide occurrence of farmland damages by wild boars over recent years.

According to the statistics and modelings on the farmland damage by wild boars, farmlands with root crops (i.e., potato and sweet potato) and rice close to forest boundaries were verified as the top priority targets to wild boars. This means that wild boars have not been recognizing the reduction of their habitat and/or the loss of common land between people and them in their forest territory. Ignorance of wild boars on the human occupation in farmlands would be finally sustainable cause of conflict between farmers and wild boars.

\section{Recommendations}

Modeling the damage sensitivity by wild boars nearby forest patches would be a good reference to understand wild life animals which have been making intensive interactions with people. As a large area of natural resource has been modified and/or changed into anthropocentric land uses, the conflict between people and wild life would much frequently happen from now on. Therefore, modeling and estimating process for understanding the behavior of wild life animals would be a mandatory progress, and it is the time to get the further study on the coexistence with wild life animals in natural resources.

Acknowledgement. This research was supported by Yeungnam University Research Grants in 2016.

\section{REFERENCES}

[1] Alexiou, P. N. (1983): Effect of feral pigs (Sus scrofa) on subalpine vegetation at Smokers Gap, ACT. - Proceedings of the Ecological Society of Australia 12: 135-142.

[2] Boitani, L., Mattei, L., Nonis, D., Corsi, F. (1994): Spatial and activity patterns of wild boars in Tuscany, Italy. - Journal of Mammalogy 75(3): 600-612.

[3] Clements, F. E. (1904): Development and Structure of Vegetation. Report of the Botanical Survey of Nebraska. - The Woodruff-Collins Printing Company, Lincoln.

[4] Elith, J., Graham, C. H., Anderson, R. P., Dudik, M., Ferrier, S., Guisan, A., Hijmans, R. J., Huettmann, F., Leathwick, J. R., Lehmann, A., Li, J., Lohmann, L. G., Loiselle, B. A., Manion, G., Moritz, C., Nakamura, M., Nakazawa, Y., Overton, J. M., Peterson, A. T., Phillips, S. J., Richardson, K., Scachetti-Pereira, R., Schapire, R. E., Soberón, J., Williams, S., Wisz, M. S., Zimmermann, N. E. (2006): Novel methods improve prediction of species' distributions from occurrence data. - Ecography 29(2): 129-151.

[5] Fielding, A. H., Bell, J. F. (1997): A review of methods for the assessment of prediction errors in conservation presence/absence models. - Environmental Conservation 24(1): 38-49.

[6] Friston, K. J., Holmes, A. P., Worsley, K. J., Poline, J. B., Frith, C. D., Frackowiak, R. S. J. (1995): Statistical parametric maps in functional imaging: A general linear approach. Human Brain Mapping 2(4): 189-210.

[7] Fu, P., Rich, P. M. (2002): A geometric solar radiation model with applications in agriculture and forestry. - Computers and Electronics in Agriculture 37(1-3): 25-35.

[8] Gormley, A. M., Forsyth, D. M., Griffioen, P., Lindeman, M., Ramsey, D. S. L., Scroggie, M. P., Woodford, L. (2011): Using presence-only and presence-absence data to 
estimate the current and potential distributions of established invasive species. - Journal of Applied Ecology 48(1): 25-34.

[9] Groot Bruinderink, G. W. T. A., Hazebroek, E. (1996): Wild boar (Sus scrofa scrofa L.) rooting and forest regeneration on podzolic soils in the Netherlands. - Forest Ecology and Management 88(1-2): 71-80.

[10] Guisan, A., Zimmermann, N. E. (2000): Predictive habitat distribution models in ecology. - Ecological Modeling 135(2-3): 147-186.

[11] Guisan, A., Edwards, T. C., Hastie, T. (2002): Generalized linear and generalized additive models in studies of species distributions: setting the scene. - Ecological Modeling 157(2-3): 89-100.

[12] Herrero, J., Fernández de Luco, D. (2003): Wild boars in Uruguay: scavengers or predators? - Mammalia 67(4): 485-492.

[13] Herrero, J., García-Serrano, A., Couto, S., Ortuño, V. M., García-González, R. (2006): Diet of wild boar Sus scrofa L. and crop damage in an intensive agroecosystem. European Journal of Wildlife Research 52(4): 245-250.

[14] Kim, J. Y., Seo, C. W., Kwon, H. S., Ryu, J. E., Kim, M. J. (2012): A study on the species distribution modeling using national ecosystem survey data. - Environmental Impact Assessment 21(4): 593-607.

[15] Kim, W. J., Park, C. H., Kim, W. M. (1998): Development of habitat suitability analysis models for wild boar (Sus scrofa): A case study of Mt. Sulak and Mt. Jumbong. - Journal of Korean Society for Geospatial Information System 16(4): 59-64.

[16] Kim, Y. K., Hong, Y. J., Min, M. S., Kim, K. S., Kim, Y. J., Voloshina, I., Myslenkov, A., Smith, G. J. D., Cuong, N. D., Tho, H. H., Han, S. H., Yang, D. H., Kim, C. B., Lee, H. (2011): Genetic status of asiatic black bear (Ursus thibetanus) reintroduced into South Korea Based on mitochondrial DNA and microsatellite loci analysis. - Journal of Heredity 102(2): 165-174.

[17] Kwon, H. S., Kim, B. J., Jang, G. S. (2016): Modelling the spatial distribution of wildlife animals using presence and absence data. - Contemporary Problems of Ecology 9(5): 515-528.

[18] Lee, M. Y., Hyun, J. Y., Lee, S. J., An, J., Lee, E., Min, M. S., Kimura, J., Kawada, S., Kurihara, N., Luo, S. J., O’Brien, S. J., Johnson, W. E., Lee, H. (2012): Subspecific status of the Korean tiger inferred by the ancient DNA analysis. - Animal Systematics, Evolution and Diversity 28(1): 48-53.

[19] Lee, S. M., Lee, W. S. (2014): Diet of the wild boar (Sus scrofa) in agricultural land of Geochang, Gyeongnam Province, Korea. - The Korea Forest Society 103(2): 307-312 (in Korean with English abstract).

[20] Massei, G., Genov, P. V. (2004): The environmental impact of wild boar. - Galemys 16: 135-145.

[21] McCollin, D. (1998): Forest edges and habitat selection in birds: a functional approach. Ecography 21(3): 247-260.

[22] McCullagh, P., Nelder, J. A. (1989): Generalized Linear Models. - Chapman \& Hall, London.

[23] Myster, R. W. (2012): Ecotones between Forest and Grassland - Springer, New York.

[24] Olson, G. S., Glenn, E. M., Anthony, R. G., Forsman, E. D., Reid, J. A., Loschl, P. J., Ripple, W. J. (2004): Modeling demographic performance of northern spotted owls relative to forest habitat in Oregon. - Journal of Wildlife Management 68(4): 1039-1053.

[25] Pavlov, P. M., Hone, J., Kilgour, R. J., Pedersen, H. (1981): Predation by feral pigs on Merino lambs at Nyngan, New South Wales. - Australian Journal of Experimental Agriculture and Animal Husbandry 21: 570-574.

[26] Peracino, V., Bassano, B. (1995): The wild boar (Sus scrofa) in the Gran Paradiso National Park (Italy): presence and distribution. - Journal of Mountain Ecology 3: 145146. 
[27] Phillips, S. J., Anderson, R. P., Schapire, R. E. (2006): Maximum entropy modeling of species geographic distributions. - Ecological Modelling 190(3-4): 231-259.

[28] Polpus, J. L., Hebblewhite, M., Heinemeyer, K. (2011): Identifying indirect habitat loss and avoidance of human infrastructure by northern mountain woodland caribou. Biological Conservation 144(11): 2637-2646.

[29] Schley, L., Dufrene, M., Kier, A., Frantz, A. C. (2008): Patterns of crop damage by wild boar (Sus scrofa) in Luxembourg over a 10-year period. - European Journal of Wildlife Research 54(4): 589-599.

[30] Scott, J. M., Heglund, P. J., Samson, F., Haufler, J., Morrison, M., Raphael, M., Wall, B. (2002): Predicting Species Occurrences: Issues of Accuracy and Scale. - Island Press, Covelo.

[31] Seo, C. W., Park, C. H. (2000): Wild Boar (Sus scrofa coreanus Heude) habitat modeling using GIS and logistic regression. - Korean Journal of Geographic Information System 6(2): 247-256.

[32] Smith, T. B. Wayne, R. K., Girman, D. J., Bruford, M. W. (1997): A role for ecotones in generating rainforest biodiversity. - Science 276: 1855-1857.

[33] Song, W. K., Kim, E. Y. (2012): A comparison of machine learning species distribution methods for habitat analysis of the Korea water deer (Hydropotes inermis argyropus). Korean Journal of Remote Sensing 28(1): 171-180.

[34] Swets, J. A. (1988): Measuring the accuracy of diagnostic systems. - Science 240(4857): 1285-1293.

[35] Yackulic, C. B., Chandler, R., Zipkin, E. F., Royle, J. A., Nichols, J. D., Grant, E. H. C., Veran, S. (2013): Presence-only modelling using MAXENT: When can we trust the inferences? - Methods in Ecology and Evolution 4(3): 236-243. 